\title{
OS DIREITOS DOS TRANSGÊNEROS BRASILEIROS E AS REGRAS BINÁRIAS DA PREVIDÊNCIA SOCIAL ${ }^{\mathrm{I}}$
}

\author{
Juliano Sguizard ${ }^{2}$ \\ Bruna da Silva Pereira Camargo ${ }^{3}$
}

RESUMO: O presente artigo tem por objetivo analisar as regras para concessão de benefícios previdenciários, com foco nas relacionadas ao tempo de contribuição e idade para aquisição de aposentadoria, e o tratamento dado aos transgêneros brasileiros. Essa temática se mostra de extrema importância quando analisamos a insegurança jurídica a que essas pessoas estão submetidas pela falta de legislação específica. Considerando que as normas legais não possuem a mesma dinamicidade da sociedade, muitos grupos acabam experimentando o que poderia ser chamado de marginalização legislativa. Ou seja, encontram-se em um limbo não alcançado por uma previsão legal específica e que garanta a aquisição de direitos básicos. Com isso, é possível perceber que a legislação previdenciária ao tratar de aposentadoria e tempo de contribuição, além de outras situações, utiliza requisitos que partem de uma ótica binária (homem/mulher), deixando de lado indivíduos que se identificam com gênero oposto ao do nascimento. Ou seja, como não há legislação que trate da situação dos transgêneros no que diz respeito a direitos previdenciários, eles ficam submetidos a decisões conflitantes baseadas em jurisprudências não pacificadas ou vinculantes dos tribunais superiores. Por isso, tendo em vista essas regras binárias, busca-se através do método dedutivo e de maneira qualitativa analisar os direitos previdenciários dos transgêneros brasileiros após o reconhecimento civil do novo gênero e de que forma a falta de previsão legal direcionada a esse grupo afeta no reconhecimento e desfrute de direitos fundamentais básicos, afetando diretamente o princípio da dignidade da pessoa humana e a qualidade de vida dessas pessoas.

Palavras-chave: Direito Previdenciário. Transgêneros. Dignidade da Pessoa Humana. Direitos Fundamentais. Benefícios Previdenciários.

\footnotetext{
I Artigo desenvolvido como Trabalho de Conclusão de Curso de Pós-Graduação Latu Senso em Direito do Trabalho, Processo do Trabalho e Direito Previdenciário do Centro UniversitárioCathedral.

${ }^{2}$ Especialista em: Direito Constitucional, Docência no Ensino Superior, Gestão Pública com ênfase em Gestão Ambiental, Saúde Indígena. Bacharel em Direito pela Faculdade de Colider. Advogado regularmente inscrito perante a OAB/MT com o no 16.483. Docente do Curso de Direito Presencial e EaD do Centro Universitário Cathedral - UNICATHEDRAL.E-mail: julianosguizardi@gmail.com

${ }^{3}$ Especialista em Direito do Trabalho, Processo do Trabalho e Direito Previdenciário. Graduanda em Direito pela Universidade Federal do Mato Grosso. Graduada em Letras pela Universidade Federal do Rio de Janeiro. Servidora Pública Federal do Tribunal Regional Federal da Primeira Região. Email: bcamargo.letras@gmail.com.
} 


\section{INTRODUÇÃO}

A Previdência Social integra a Seguridade Social e ambas constituem o rol de direitos sociais na Constituição Federal de 1988. O texto constitucional garante o direito à previdência em seu artigo 6우 que dispõe:

Art. 6․ São direitos sociais a educação, a saúde, a alimentação, o trabalho, a moradia, o transporte, o lazer, a segurança, a previdência social, a proteção à maternidade e à infância, a assistência aos desamparados, na forma desta Constituição. (BRASIL, I988)

A partir da análise desse artigo é possível perceber a intenção do legislador em garantir a todos os indivíduos esses direitos descritos, dentre eles a previdência social, de forma universal e sem qualquer tipo de distinção. Por isso, a universalidade da cobertura e do atendimento está expressamente disposta no artigo 194, parágrafo único, I, da Constituição Federal, dispondo:

Art. 194. A seguridade social compreende um conjunto integrado de ações de iniciativa dos Poderes Públicos e da sociedade, destinadas a assegurar os direitos relativos à saúde, à previdência e à assistência social.

Parágrafo único. Compete ao Poder Público, nos termos da lei, organizar a seguridade social, com base nos seguintes objetivos:

I - universalidade da cobertura e do atendimento; (...). (BRASIL, I988)

Apesar do esforço do legislador em garantir a todos os direitos constitucionais, alguns grupos permanecem sem amparo legal em questões específicas. Os transgêneros brasileiros, por exemplo, experimentam a ausência legal de normas que garantam a efetivação de direitos fundamentais básicos como a previdência social. Ao analisar o que dispõe a lei que regulamenta a concessão de benefícios previdenciários é possível perceber que tratam de forma binária (homem-mulher) seus beneficiários. Tendo como base para definição do gênero aquele descrito no momento de seu nascimento. Sendo assim, as pessoas que se identificam com gênero oposto ao definido no nascimento deixam de ser contempladas por esses direitos descritos binariamente.

A falta de legislação que os assegure de forma direta e objetiva os direitos previdenciários é um flagrante ataque ao princípio da dignidade da pessoa humana que, como princípio constitucional, deve ser assegurado a todo indivíduo. Considerando as várias possibilidades de interpretação e utilização desse princípio, será considerado neste 

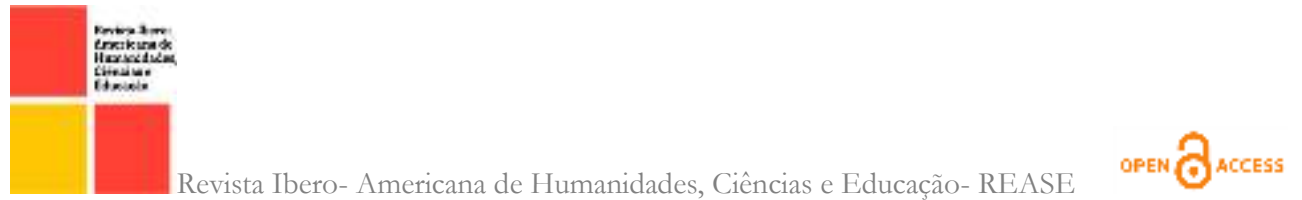

trabalho a definição, os critérios de utilização e elementos da dignidade da pessoa humana segundo Luís Roberto Barroso. Um dos elementos essenciais trazidos por Barroso em artigo sobre a dignidade da pessoa humana no Direito Constitucional contemporâneo é a autonomia da vontade no respeito à dignidade. Sendo assim, quando uma pessoa é impedida de desfrutar de seus direitos constitucionais a partir do gênero com o qual se identifica há uma violação a sua dignidade e individualidade, causando traumas e impedindo uma sadia qualidade de vida. Ou seja, quando o indivíduo ao se identificar com gênero oposto ao de seu nascimento fica impedido de ter sua vontade respeitada perante o Estado e sociedade ele passa a ser marginalizado pela legislação pátria e punido de forma cruel e injusta.

Por isso, a falta de legislação específica para os transgêneros afeta diretamente o direito à aposentadoria. Sendo esse direito fundamental para dignidade, além de ser dever do Estado garantir que todas as pessoas desfrutem de uma vida com qualidade após o período de atividade laboral também deve ser resguardada a universalidade de acesso às benesses previdenciárias. $\mathrm{O}$ reconhecimento civil e social deve estar assegurado como forma de preservação da individualidade e dignidade, garantindo assim que essas pessoas não sejam obrigadas a recorrer judicialmente para garantir o que a Constituição já prevê como direito. Além disso, é preciso regulamentar de forma justa e clara sua condição evitando a insegurança jurídica e decisões conflitantes e baseadas em subjetividade quando não há o devido amparo legal. No entanto, os transgêneros ainda não desfrutam de forma direta e universal dessas garantias constitucionais. Esses indivíduos experimentam uma omissão legislativa e insegurança jurídica quando se trata do tema previdenciário. Afinal, as regras para concessão de benefício previdenciário, em especial aposentadoria, são baseadas em critérios binários (masculino e feminino). Ou seja, as pessoas que passam pela transição de gênero precisam enfrentar o limbo legislativo e se apoiarem em decisões esparsas acerca do tema. Nesse momento surge o questionamento: como garantir que os direitos previdenciários dos transexuais sejam garantidos após a retificação do registro civil inclusive às pessoas que optam por não realizar a cirurgia de transgenitalização?

A análise de como a legislação previdenciária pode regulamentar a situação dos transexuais não parece tarefa fácil. A resposta para esse questionamento, parte da análise dos diversos julgamentos relacionados ao tema pelos tribunais superiores, bem como, do 
estudo da atual legislação previdenciária como parâmetro para encerrar esse limbo legal acerca dos direitos dos transgêneros. Nesse contexto, deve ser levado em consideração inclusive aqueles que optam pela não cirurgia, no entanto se identificam e passam por toda transição de gênero. Afinal, não podem continuar em situação de desamparo legislativo tendo que recorrer a decisões esparsas e subjetivas para garantia de direitos fundamentais e individuais. Em paralelo à jurisprudência e a legislação pátria, destaca-se a necessidade da pesquisa em doutrinas e artigos científicos para um maior entendimento sobre o tema.

Trata-se de uma pesquisa básica, geradora de novos conhecimentos que auxiliam o desenvolvimento de estudos para as presentes e futuras gerações, já que as questões relativas à previdência social representam uma demanda atual e urgente no respeito à dignidade dos transgêneros. Para tanto, aborda-se o tema de maneira qualitativa, visando que esta contribuirá para a análise das normas e regulamentações que tratam do tema e como esses dispositivos podem ser utilizados no respeito aos direitos das pessoas que apresentam transtorno de identidade de gênero. Além disso, contribuirá para análise de como o Estado poderá atuar para que esses direitos sejam resguardados legislativamente e de fato garantidos.

Quanto ao objetivo, a pesquisa será explicativa, pois almeja demonstrar a maneira como os transgêneros são tratados na legislação previdenciária atual e de que forma poderão ter seus direitos reconhecidos visando sua "existência” perante a Previdência Social na busca por uma vida e aposentadoria dignas de acordo com o gênero com o qual se identificam.

Serão utilizados o método bibliográfico e o método de procedimento monográfico, que nos proporciona textos de apoio para o desenvolvimento desta pesquisa, como artigos científicos, obras literárias, manuais, doutrinas relacionadas aos Direitos Fundamentais, Direitos Humanos e Dignidade da pessoa humana, assim, facilitando a busca pelo conhecimento. $\mathrm{O}$ método de abordagem será dedutivo, partindo da análise das normas que tratam sobre Previdência Social de modo geral para, a partir disso, analisar as questões referentes a esse tema com foco nos transgêneros.

Portanto, este projeto visa apresentar soluções viáveis para o respeito aos transgêneros em seus direitos previdenciários, tendo como foco a concessão ou readequação de benefício. Além de expor a situação atual dessas pessoas quando 
necessitam recorrer ao judiciário como meio de garantir seus direitos e se deparam com a lacuna legislativa e com a insegurança jurídica causada por essa ausência de dispositivo na legislação pátria.

\section{TRANSGÊNEROS E DIGNIDADE DA PESSOA HUMANA}

"Maior violência patriarcal e colonial é desrespeitar e questionar a identidade de gênero de uma pessoa."

M. Cambrollé

O processo de identificação e transição de gênero não é fácil para quem se encontra nessa situação. A condição de estar "fora" do padrão socialmente imposto como normal deixa a pessoa em situação de vulnerabilidade e constante julgamento social. No entanto, é preciso fazer valer sua vontade e autonomia para que possa viver sua vida da forma como escolheu e com qualidade e respeito tanto da sociedade como do Estado.

O caminho percorrido para aceitação passa não só pelos julgamentos sociais, como também por uma longa jornada de identificação com gênero oposto ao do nascimento, de terapias, de tratamento hormonal, culminando na cirurgia de transgenitalização ou não. Ou seja, impedir que a pessoa possa se desenvolver da forma como se reconhece ou impedir que tenha direitos garantidos por conta disso é de uma crueldade imensa. A Dra. Gabrielle Bezerra Sales Sarlet em seu artigo sobre transgenerismo infantil relata a importância ao respeito da vontade e como a imposição pode ser prejudicial para seu desenvolvimento.

(...) o aprisionamento absoluto do corpo à dimensão biologicamente préestabelecida consiste em uma forma sutil, perversa e cruel de reducionismo da pessoa e de suas múltiplas dimensões. (SARLET, 2018, p.52)

Ou seja, ao impor que uma pessoa aja e se desenvolva conforme o gênero biológico de seu nascimento quando na verdade se identifica com o oposto é uma forma de reducionismo e crueldade. Deixando de lado suas vontades e anseios fazendo com que seus direitos e sua dignidade sejam anulados para atender um clamor social a algo tido como “normal”. Ao anular os anseios dessas pessoas há uma nítida violação à sua dignidade enquanto ser de direitos.

A dignidade da pessoa humana é um argumento amplamente utilizado para defender ou atacar determinada posição. Por tratar-se de um instrumento com uma noção que tende à subjetividade, podendo ser utilizado por ambas as partes, necessita de uma 

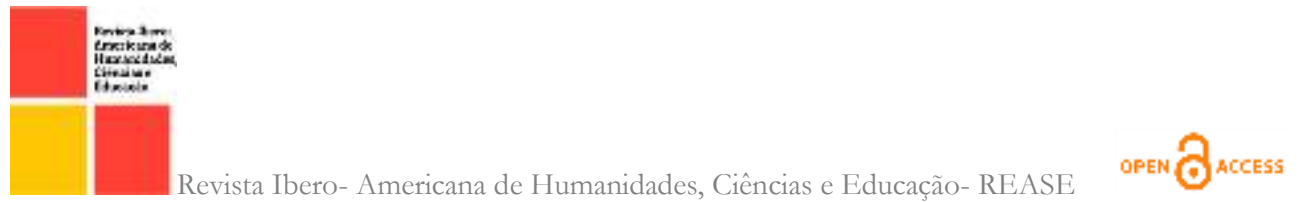

conceituação que busque certa objetividade. Sem isso, poderia cair na diminuição de sua importância por uma utilização indiscriminada. Por isso, Luís Roberto Barroso em seu estudo sobre a dignidade da pessoa humana no direito contemporâneo busca apresentar elementos que tornem esse conceito mais objetivo. Evitando seu apontamento de forma superficial e indiscriminada, alçando-o, assim, ao posto de princípio fundamental e de extrema importância na resolução de conflitos. Sem, contudo, esquecer seu caráter dinâmico que, segundo Luís Roberto, “(...) varia no tempo e no espaço, sofrendo o impacto da história e da cultura de cada povo (...)" (BARROSO, 20Io, p. 8). Um dos elementos que Barroso utiliza para caracterizar o princípio da dignidade da pessoa humana é justamente a autonomia da vontade. Ou seja, ser capaz fazer escolhas e tê-las respeitadas social e juridicamente. Essa violação pode ser caracterizada de várias formas, uma das mais comuns ao tratar dos transgêneros é justamente a imposição de um gênero a partir de padrões morais e tidos como normal pela sociedade. Essa tentativa de adequação a um padrão social e que carrega a ideia utópica de servir a todos os indivíduos além de ser uma prática cruel e violadora de direitos também se apresenta como obstáculo quase que instransponível quando não se tem as garantias mais essenciais preservadas e asseguradas.

Sendo assim, Barroso caracteriza a autonomia da vontade como elemento essencial ao desenvolvimento da personalidade do indivíduo de forma digna.

A autonomia é o elemento ético da dignidade, ligado à razão e ao exercício da
vontade na conformidade de determinadas normas. A dignidade como autonomia
envolve, em primeiro lugar, a capacidade de autoderteminação, direito do indivíduo
de decidir os rumos da própria vida e de desenvolver livremente sua
personalidade. Significa o poder de fazer valorações morais e escolhas existenciais
sem imposiçóes externas indevidas. (BARROSO, 201o, p. 24)

Portanto, não há que se falar em dignidade da pessoa humana sem que haja o respeito a sua vontade. Essa autonomia da vontade deve ser respeitada não só socialmente, mas também legalmente. Sendo assim, ao reconhecer seu gênero como oposto ao de seu nascimento o indivíduo deve ter seus direitos reconhecidos e efetivados pelo Estado, além de ter sua vontade socialmente aceita livre de qualquer discriminação ou estigma. Outros dois elementos são apontados pelo autor como essenciais à dignidade humana. São eles o valor intrínseco da pessoa humana que revela-se como "Um valor que não tem preço." (BARROSO, 2oro, p. 22), sendo o que Barroso define como "elemento ontológico da dignidade” (BARROSO, 2010, p. 2I), e o valor comunitário ou valor social da pessoa 
humana sendo que aquele que “(...) abriga o seu elemento social. $\mathrm{O}$ indivíduo em relação ao grupo.” (BARROSO, 2010, p.27). Por consequência, esses três elementos revelam-se como conteúdos essenciais no pensamento acerca da dignidade. Ou seja, auxiliam o entendimento de seu conceito, definição e objetividade quando utilizado nas mais diversas situações e em aplicação a qualquer indivíduo.

Tendo como norte a dignidade da pessoa humana para respeito aos direitos dos transgêneros, vale destacar a ideia que Ingo Sarlet traz desse princípio como limite ao poder estatal, na medida em que não pode haver interferência estatal visando sua violação, bem como também implica um dever do Estado em manter políticas públicas de proteção e efetivação desse princípio (SARLET, 2019, p.89). Outro ponto importante destacado pelo autor é a ideia de que a dignidade não está apenas em situações reconhecidas pelo Direito, tão pouco apenas à medida que este a reconhece (SARLET, 2019, p. 52). Esse pensamento é desenvolvido pelo autor a partir de uma análise das constantes evoluções sociais, ou seja, não pode a dignidade está atrelada ao Direito de forma taxativa, já que a sociedade está em constante mudanças. Corroborando com esse pensamento, Maria Berenice Dias aponta que:

O fato de não haver previsão legal não significa inexistência de direito à tutela jurídica. Ausência de lei não quer dizer ausência de direito, nem impede que se extraiam efeitos jurídicos de determinada situação fática. A falta de previsão específica nos regramentos legislativos não pode servir de justificativa para negar a prestação jurisdicional ou de motivo para deixar de reconhecer a existência de direito. O silêncio do legislador precisa ser suprido pelo juiz, que cria a lei para o caso que se apresenta a julgamento. $\mathrm{Na}$ omissão legal, deve o juiz se socorrer da analogia, costumes e princípios gerais de direito. (DIAS, 2007, p. 14)

Ou seja, a falta de previsão legal não pode servir como justificativa para que direitos não sejam garantidos ou para que a dignidade da pessoa humana seja deixada de lado. Por outro lado, deve esse princípio acompanhar os novos rumos sociais para garantir sua eficácia. Sendo assim, ainda que não haja legislação específica acerca dos direitos previdenciários dos transgêneros, estes devem ser respeitados como forma de garantia ao princípio da dignidade a essas pessoas.

Dessa forma, os transgêneros devem ter seu direito à autonomia respeitado ao se identificarem com gênero diverso do biológico. Além do dever estatal em garantir a efetivação de seus direitos fundamentais é preciso que haja políticas públicas de aceitação social. Afinal, segundo dados da Associação Nacional de Travestis e Transexuais, a 
expectativa de vida dessas pessoas é de 35 anos. Demonstrando a morte precoce desse grupo por diversos fatores, entre eles a violência desencadeada pelo preconceito e discriminação. Por isso, para que a dignidade da pessoa humana seja garantida aos transgêneros é preciso que eles estejam vivos e desfrutando em igualdade dos direitos destinados a todos os cidadãos. Sem isso não há como legislar acerca de benefícios previdenciários para um grupo que sequer chega à idade de adquiri-los. Portanto, é essencial que se fale e discuta acerca da dignidade da pessoa humana quando se trata de direitos dos transgêneros.

\section{O DIREITO CONTEMPORÂNEO E OS REFLEXOS PRECIDENCIÁRIOS}

A forma como uma sociedade se estrutura está em constante alteração, as mudanças ocorrem de maneira dinâmica e contínua. Em contrapartida a legislação e o judiciário não caminham na mesma velocidade dessas alterações e com isso precisam ser provocados para que atuem na mudança de posicionamentos. Ou seja, cabe à sociedade o despertar desses órgãos para as novas realidades e anseios. Sendo assim, não seria diferente com o reconhecimento jurídico dos direitos dos transgêneros.

Ainda em 2011, Luís Roberto Barroso em seu artigo sobre o respeito às uniões homoafetivas já destacava acerca da evolução social em comparação às mudanças legislativas e judiciais. Ao apontar casos de intolerância e discriminação o autor comenta que "Os tempos, no entanto, estão mudando. Progressivamente, as relações homoafetivas vêm conquistando aceitação em respeito." (BARROSO, 20II, p. 107). Ou seja, quase ro anos atrás ainda se discutia sobre o reconhecimento das relações homoafetivas, questão hoje pacificada e caracterizadora das novas configurações familiares. Assim como o conceito de família tomou outro significado para atender às novas realidades de relacionamentos e arranjos domiciliares, o direito alterou o conceito de união estável para atender aos anseios sociais. Revela-se aqui o fenômeno da mutação constitucional, onde se altera o sentido sem que a letra da lei seja modificada. Já que em seu artigo 226 , $\$ 3^{\circ}$, a Constituição Federal dispõe que "Para efeito da proteção do Estado, é reconhecida a união estável entre homem e mulher como entidade familiar (...)" (BRASIL, 1988). Considerando este artigo, todas as pessoas que estivessem em um relacionamento homoafetivo não desfrutavam da proteção estatal, do regime de sucessão ou qualquer outro dispositivo que levasse em consideração a 

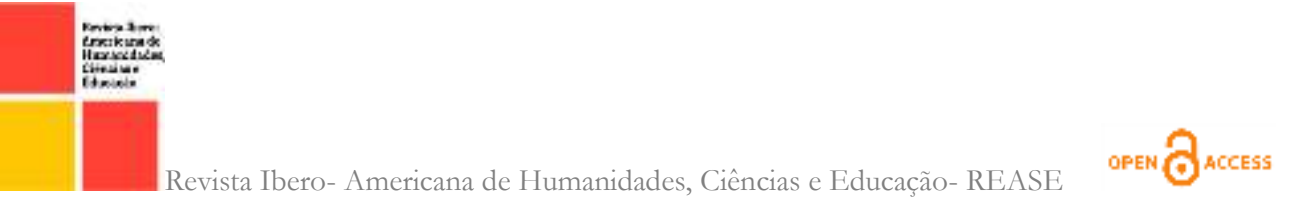

definição constitucional de união estável. No entanto, o julgamento da Ação Direta de Inconstitucionalidade (ADI) 4277 e da Arguição de Descumprimento de Preceito Fundamental (ADPF) 132, consolidou o entendimento de que as uniões homoafetivas recebessem o mesmo tratamento daquelas constituídas por heterossexuais.

O reconhecimento da união estável entre pessoas do mesmo sexo reflete em diversas áreas do Direito. Com a matéria previdenciária não seria diferente, pois a partir desse reconhecimento é possível que um funcionário acrescente outra pessoa do mesmo sexo como dependente para fins de pensão por morte, por exemplo. Inclusive, a ADPF 132 foi ajuizada pelo governo do Rio de Janeiro buscando o reconhecimento das uniões homoafetivas de funcionários públicos civis do estado. Ou seja, buscou-se um direito para que todos fossem conhecidos e pudessem desfrutar das mesmas garantias constitucionais, fazendo valer a igualdade, liberdade, dignidade da pessoa humana entre outros.

A Previdência Social passou por alterações decorrentes do julgamento da ADI 4277 no tocante também ao salário-maternidade. Ao ter os direitos das uniões estáveis reconhecidos, os casais homoafetivos passaram a desfrutar das condições seguradas pela previdência. Dentre elas, aquelas direcionadas à família já que passaram a se enquadrar em uma nova configuração familiar. Sendo assim, os benefícios previdenciários garantidos em decorrência de parto, aborto não criminoso, adoção ou guarda para fins de adoção puderam ser garantidos a essas pessoas. Com isso, resta pacificado a possibilidade de recebimento desses benefícios por aqueles em uniões homoafetivas. Um ponto acerca dos transgêneros e o salário maternidade é discutido por LAZZARIN e SILVA, em que pontuam a possibilidade de uma mulher trans receber o auxílio ainda que seja o caso de uma gestação solidária. Pontuam os autores que:

\footnotetext{
Assim, a concessão do benefício salário-maternidade não deve estar associada a questões de gênero. $O$ fato gerador do benefício diz respeito à ocorrência de um parto, pouco importando as características do corpo que tiver parido e dos comportamentos associados a ele. Quando uma mulher cis ou um homem trans dá à luz, uma pessoa dá à luz, e este deveria ser o fato gerador do benefício. (LAZZARIN; SILVA, 2019, p. 42)
}

Portanto, ainda que o reconhecimento seja para pessoas em uniões homoafetivas, sem qualquer menção aos transgêneros, por analogia nada impede que essas pessoas também possam desfrutar dos benefícios previdenciários referentes ao salário- 
maternidade. Impedindo assim que uma decisão que veio para corrigir uma injustiça social acabe por provocar outra.

O transexualismo passa por discussões além das matérias jurídicas, bem antes de se tornar objeto de disputas judiciais já integrava os conteúdos médicos. Por muitos anos foi considerado como doença psiquiátrica. As pessoas que se identificassem de forma diversa da considerada normal eram levadas a tratamento e tidas como doentes. Essa situação perdurou por muitos anos e somente em 2018 a OMS, em divulgação à nova lista da Classificação Internacional de Doenças (CID II), retirou a transexualidade da categoria de transtornos psiquiátricos. No entanto, essa nova classificação só entrará em vigor em 2022, com a classificação de transexualismo como incongruência de gênero. Essa vitória é importante para que a sociedade tenha conhecimento de que a incongruência de gênero não é doença, sendo assim não há espaço para discussões ou imposições de cura.

É possível perceber por essas e tantas outras decisões que os anseios sociais são alterados de acordo com o momento histórico, com as experiências vividas e culturas em que os indivíduos estão inseridos. Sendo impossível que o legislador consiga acompanhálos. Por isso, de extrema importância que os órgãos sejam provocados para que alterem entendimentos na busca por garantir igualdade e dignidade a todos, principalmente às minorias que parecem padecer ainda mais com os atrasos legislativos, como o caso dos transgêneros frente às regras binárias da Previdência Social.

\section{OS TRANGÊNEROS E A PREVIDÊNCIA SOCIAL}

Precipuamente à discussão acerca do tratamento dado aos transgêneros pela legislação previdenciária, cumpre destacar pequena definição do termo aqui utilizado. Os transgêneros, termo aqui utilizado como gênero em que os transexuais estão englobados, são aquelas pessoas que se identificam com gênero oposto ao de seu nascimento. $O$ Ministro Luís Roberto Barroso, enquanto relator da ADPF 527, citando Maria Berenice Dias define:

A mulher transexual é a pessoa que, nascida com o sexo biológico masculino, se percebe como uma mulher e, portanto, tem identidade de gênero feminina. $O$ homem transexual é a pessoa que, nascida com o sexo biológico feminino, se percebe como homem e tem identidade de gênero masculina. As pessoas transexuais são, portanto, aquelas que têm uma percepção de que seu corpo é 
inadequado à forma como se sentem, e buscam ajustá-lo à imagem de gênero que têm de si. (ADPF 527, 2019, p.8)

Esse julgamento foi de extrema importância aos transgêneros aos definir que as mulheres trans em regime carcerário pudessem cumprir sua pena em estabelecimento prisional feminino. Efetivando, assim, o respeito à identidade de gênero dessas pessoas que já enfrentam o estigma do sistema prisional. Apesar de tantas mudanças positivas que envolvem as pessoas trans, a legislação previdenciária ainda carece de ajustes para reconhecimento de direitos a esses indivíduos.

A Previdência Social se apresenta como direito fundamental e sua garantia é de extrema importância para que os indivíduos possam desfrutar de uma vida digna, principalmente quando se encontram em situação que impede o labor. O Estado tem o dever constitucional de promover sua garantia e efetivação a todos, sem qualquer tipo de distinção. No entanto, a legislação previdenciária, mesmo após a recente reforma aprovada pelo Congresso Nacional, deixa de lado os transgêneros. Esse grupo permanece diante de uma omissão legislativa e conta apenas com jurisprudências e julgados como fonte na busca por seus direitos.

A Ação Direta de Inconstitucionalidade n. 4.275 foi proposta com a finalidade de garantir aos transexuais o direito de alteração do nome e prenome em seus registros civis, ainda que não tivesse ocorrido a cirurgia de retificação sexual. Após longos anos em tramitação, o Superior Tribunal Federal decidiu dar provimento à demanda. Com isso, não seria preciso acionar o judiciário para que as alterações fossem feitas, bastando apenas o pedido administrativo. Dispondo:

DIREITO CONSTITUCIONAL E REGISTRAL. PESSOA TRANSGÊNERO. ALTERAÇÃO DO PRENOME E DO SEXO NO REGISTRO CIVIL. POSSIBILIDADE. DIREITO AO NOME, AO RECONHECIMENTO DA PERSONALIDADE JURÍDICA, À LIBERDADE PESSOAL, À HONRA E À DIGNIDADE. INEXIGIBILIDADE DE CIRURGIA DE TRANSGENITALIZAÇÃO OU DA REALIZAÇÃO DE TRATAMENTOS HORMONAIS OU PATOLOGIZANTES. I. O direito à igualdade sem discriminações abrange a identidade ou expressão de gênero. 2. A identidade de gênero é manifestação da própria personalidade da pessoa humana e, como tal, cabe ao Estado apenas o papel de reconhecê-la, nunca de constituí-la. 3. A pessoa transgênero que comprove sua identidade de gênero dissonante daquela que lhe foi designada ao nascer por autoidentificação firmada em declaração escrita desta sua vontade dispõe do direito fundamental subjetivo à alteração do prenome e da classificação de gênero no registro civil pela via administrativa ou judicial, independentemente de procedimento cirúrgico e laudos de terceiros, por se tratar de tema relativo ao direito 
fundamental ao livre desenvolvimento da personalidade. 4. Ação direta julgada procedente. (ADI 4.275, STF, 2019)

Essa foi uma importante vitória na luta pelos direitos dos transexuais e mais tarde foi confirmada pelo julgamento do RE 670.422/RS, também pelo STF, vedando, inclusive que o termo transgênero fosse incluído no novo registro. Evitando, assim, possível estigmatização ou preconceito e respeitando a liberdade, privacidade e individualidade dos indivíduos que venham a requerer essa alteração. Essas duas decisões foram muito importantes no reconhecimento de direitos como imagem, individualidade, dignidade da pessoa humana para essas pessoas. No entanto, representam apenas o início de uma transição jurídica para o acolhimento e respaldo legal aos transgêneros.

Apesar desse reconhecimento dado pelo STF os transgêneros ainda experimentam a falta de regulamentação previdenciária específica. Atualmente a legislação que trata dos assuntos previdenciários no Brasil passou por uma grande reforma (EC 103/2019) na tentativa de aproximar a lei da realidade social dos brasileiros. No entanto, continuou a apresentar critérios baseados na ótica binária (homem/ mulher) e deixando de lado essa categoria. Mesmo em temas de grande relevância social como tempo de contribuição e idade para aposentadoria os transgêneros continuam sem critérios próprios. Ou seja, atualmente o indivíduo que se identifica com gênero diverso do biologicamente determinado em seu nascimento não encontrará amparo na legislação pátria sobre Direito Previdenciário quando for buscar concessão ou readequação de seu benefício.

O contraste formado pelo reconhecimento civil do gênero com o qual o indivíduo se identifica e falta de regras acerca da temática previdenciária demonstram a dificuldade e a batalha que essas pessoas precisam enfrentar para que tenham direitos básicos respeitados. Lopes (2015, p. 16) afirma em estudo que "da mesma forma como ocorre com outros órgãos, na Previdência Social o transexual deve contrair e assumir todos os direitos e deveres de seu gênero". Ora, se o Estado reconhece que podem ter seus registros civis alterados por via administrativa não deveria estender essas alterações ao âmbito previdenciário? A reposta apesar de parecer clara envolve questões complexas e que justificam a relevância da discussão acerca desse tema.

A necessidade de uma legislação previdenciária específica é um tema urgente, pois não podem essas pessoas ficarem a mercê de doutrinas e julgados que são determinados de 

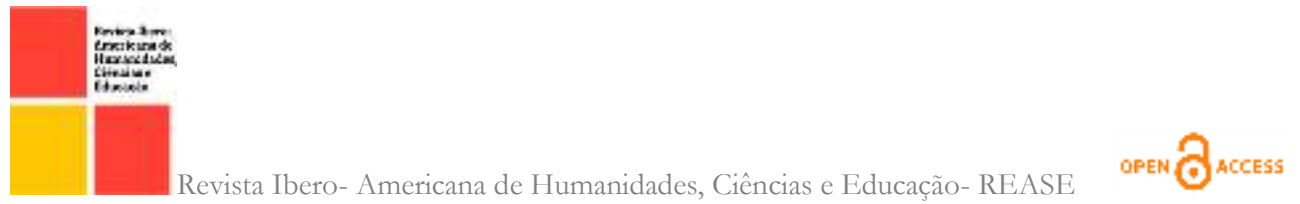

forma subjetiva e sem respaldo legal. Tendo, assim, sua individualidade, honra, imagem e dignidade severamente desrespeitados. Afinal, encontram-se "nas mãos" dos magistrados e julgadores que tomam decisões de acordo apenas com entendimentos esparsos e divergentes, acabando por decidirem de acordo com suas próprias convicções individuais. Robson Ribeiro em artigo sobre a situação dos transgêneros frente a Previdência Social relata a subjetividade dessas decisões que são tomadas sem respaldo legal específico. Ao discorrer sobre a perda da pensão pelo filho transexual de um ex-militar no ano de 2017 aponta para a fragilidade das fontes que os magistrados utilizam para embasar suas decisões. Destacando na decisão citada que “(...) o exemplo do magistrado foi uma situação hipotética e, ainda, não se pode dizer que os demais órgãos e juízes decidirão da mesma maneira." (RIBEIRO, 2020). Ou seja, essas circunstâncias colocam os transgêneros numa total insegurança jurídica, onde os magistrados podem se valer de fatos hipotéticos para embasar decisões cruciais na vida daqueles indivíduos.

A readequação do benefício de acordo com o novo gênero passa por questionamentos que não são respondidos por completo pelas frágeis fontes disponíveis. Um exemplo disso é a forma como o INSS irá julgar esses pedidos, já que se o critério da 1634 cirurgia de transgenitalização aparecer como pré-requisito acabaria por excluir aqueles que passam por todo tratamento e optam por não realizá-la. Por outro lado, a mera declaração de vontade para alteração dos registros abre margem a fraudes, considerando que a readequação está diretamente ligada ao tempo de contribuição e aposentadoria. Ou seja, sem critérios objetivos e legalmente dispostos uma pessoa de má-fé poderia simplesmente se declarar pertencente a outro gênero na busca por benefícios que não lhe são devidos. Gerando rombo nas contas públicas e ainda mais estigmatização e preconceito com aqueles que realmente se identificam com gênero oposto ao do nascimento. Enquanto isso, as pessoas que realmente necessitam do auxílio previdenciário ficam desamparadas e veem seus direitos negados por essa omissão legal.

Considerando que a diferença para aquisição da aposentadoria entre homens e mulheres, atualmente, é de três anos (62 anos para mulheres e 65 anos para homens), a depender da transição do indivíduo ele terá mais ou menos tempo a contribuir. É justamente nesse ponto que o legislador deixou de lado os transgêneros. Afinal, não há parâmetro legal que oriente o INSS a considerar a nova contribuição a partir da retificação 

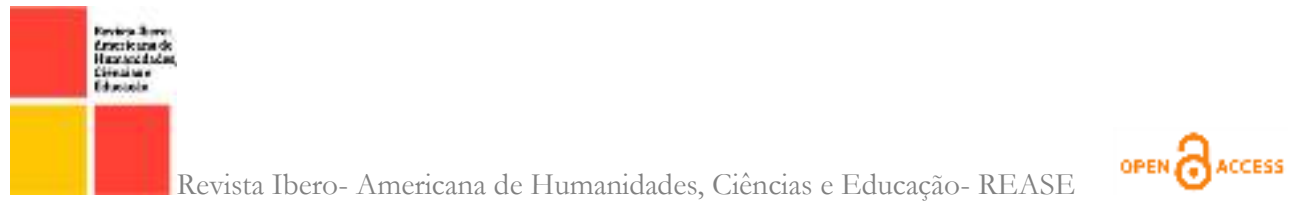

do registro civil, ou a partir do início do tratamento, ou ainda no momento do pedido do benefício. Com isso, que deseja readequação do benefício de acordo com o novo gênero não encontra na legislação atual a forma como será calculado seu tempo de contribuição ou idade para concessão da aposentadoria. Tendo que se "encaixar" nas regras existentes, ferindo seu direito de escolha e autonomia da vontade mesmo após a retificação em seu registro civil. Enfrentado, assim, uma nova batalha de aceitação perante os órgãos que lidam com as questões previdenciárias.

Diante de todo exposto, o direito previdenciário dos transgêneros deve ser tratado com máxima urgência na busca pela garantia de sua dignidade e respeito a sua autonomia de vontade. Além disso, o reconhecimento do gênero com o qual se identifica não pode ser apenas na esfera civil, deve também ser acompanhado pelos órgãos previdenciários na garantia de seus benefícios, em especial sua aposentadoria como manutenção de uma vida digna durante e após seu período laboral.

As recentes vitórias alcançadas por esse grupo na busca pelo reconhecimento social e jurídico são marcos importantes para o país. No entanto, um tema de grande relevância não só para o Direito Previdenciário como para outras áreas, a exemplo dos Direitos Humanos, não pode ser regulamentado apenas por jurisprudências e doutrinas, sendo urgente sua tratativa pelos legisladores. Somente com regras específicas e o preenchimento dessa lacuna na legislação brasileira é que esses indivíduos poderão ter suas vidas e seus direitos respeitados de forma igualitária como determina a Constituição Federal.

\section{CONSIDERAÇÕES FINAIS}

Diante do exposto, torna-se possível perceber que os indivíduos transexuais estão em situação de insegurança jurídica pela falta de legislação previdenciária específica. Com isso, acabam por recorrer a jurisprudência e decisões conflitantes quando se trata de concessão ou readequação de benefício de acordo com o gênero com o qual se identificam. Essa situação é de flagrante desrespeito a direitos fundamentais e ao princípio da dignidade da pessoa humana.

Os recentes julgados de tribunais superiores demonstram um avanço na busca pelos direitos dessas pessoas, mas ainda são insuficientes para garantia de uma vida 

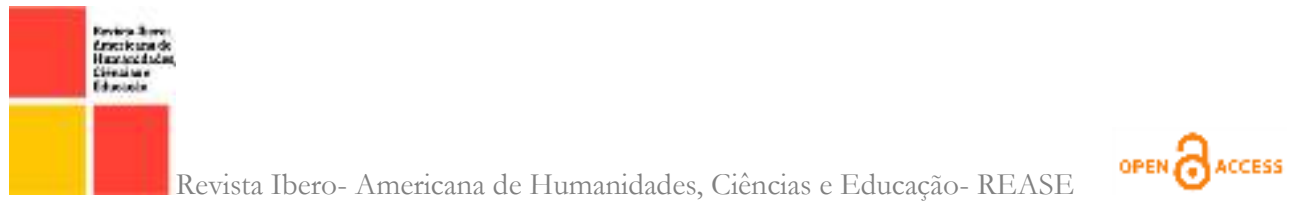

plenamente digna. Afinal, reconhecem algumas situações e deixam outras ainda no limbo legislativo. Ou seja, apesar de todos os avanços sociais referentes à identidade de gênero, a legislação caminha em passos lentos na garantia e efetivação da igualdade aos transgêneros.

Por isso, de extrema importância que a discussão acerca do preenchimento dessa lacuna legal seja constante. Somente com a edição de uma lei que preveja de forma objetiva a situação dos transgêneros brasileiros é que essas pessoas poderão ter seus direitos efetivados e não ficarão à mercê de julgados e decisões divergentes causadores de imensa insegurança jurídica. Com isso, além do reconhecimento legal elas terão também o reconhecimento do Estado e, consequentemente, da sociedade. Esses três pontos: legislação, Estado e sociedade é que podem garantir a efetivação de direitos garantidos a todos os cidadãos, proporcionando uma vida digna a todos que se identificam com gênero oposto ao de seu nascimento.

\section{REFERÊNCIAS}

BARROSO, Luís Roberto. Curso de direito constitucional contemporâneo: os conceitos fundamentais e a construção do novo modelo. 8. ed. São Paulo: Saraiva Educação, 2019.

BARROSO, Luís Roberto. A Dignidade da Pessoa Humana no Direito Constitucional Contemporâneo: Natureza Jurídica, Conteúdos Mínimos e Critérios de Aplicação. Versão provisória para debate público. Mimeografado, dezembro de 2010.

BARROSO, Luís Roberto. Diferentes, mas iguais: o reconhecimento jurídico das relações homoafetivas no Brasil. Revista Brasileira de Direito Constitucional - RBDC - n. 17, p. I05-138, jan./jul. 20II. Disponível em: http://www.esdc.com.br/RBDC/RBDC-I7/RBDCI7-105-

Arti-

go_Luis_Roberto_Barroso_(Diferentes_mas_iguais_o_reconhecimento_juridico_das_relacoes _homoafetivas_no_Brasil).pdf. Acessado em I2/05/2020.

BRASIL. Constituição Federal da República Federativa do Brasil de 1988. Disponível em: http://www.planalto.gov.br/ccivil_03/constituicao/constituicao.htm. Acessado em $28 / 02 / 2020$.

Emenda Constitucional $\mathrm{n}^{\circ}$ 103, de 12 de novembro de 2019. Disponível em: http://www.planalto.gov.br/ccivil_03/constituicao/emendas/emc/emcio3.htm. Acessado em: $2 \mathrm{I} / 02 / 2020$. 

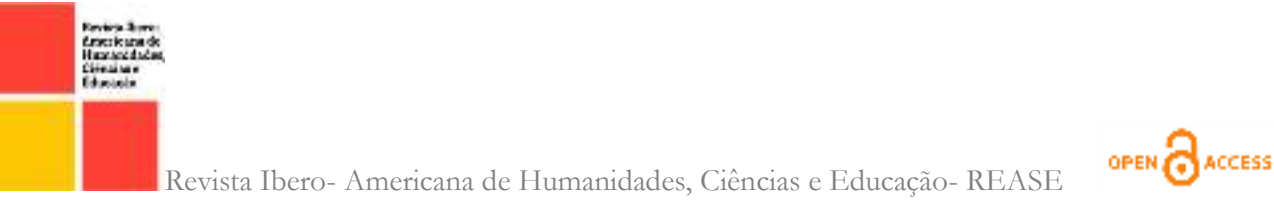

OMS divulga nova Classificação Internacional de Doenças (CID II). OMS, I8 de junho de 2or8. Disponível em: https://www.paho.org/bra/index.php?option=com_content $\&$ view $=$ article $\&$ id=5702:omsdivulga-nova-classificacao-internacional-de-doencas-cid-ıI\&Itemid=875. Acessado em: $18 / 05 / 2020$.

Supremo Tribunal Federal. Ação Direta de Inconstitucionalidade $n$. 4.275. Requerente: Procuradoria Geral da República. Ministro Relator: Marco Aurélio. Brasília, 2I jul. 2009. $\quad$ Disponível em: http://www.stf.jus.br/portal/geral/verPdfPaginado.asp? id=4002II\&tipo=TP\&descricao $=\mathrm{A}$ DI\%2F 4275 . Acessado em 27/o2/2020.

- Supremo Tribunal Federal. Ação Direta de Inconstitucionalidade $n$. 4.277. Requerente: Procuradoria Geral da República. Ministro Relator: Aures Britto. Brasília, o5 de maio de 2011. Disponível em: http://redir.stf.jus.br/paginadorpub/paginador.jsp?doc TP=AC\&docID=628635. Acessado em Io/o5/2020.

. Supremo Tribunal Federal. Arguição de Descumprimento de Preceito Fundamental n. 132. Requerente: Governo do Estado do Rio de Janeiro. Ministro Relator: Ayres Britto. Brasília, o5 de maio de 20II. Disponível em: http://redir.stf.jus.br/paginadorpub/paginador.jsp?doc TP $=\mathrm{AC} \& \operatorname{doc} I D=628633$. Acessado em $15 / 05 / 2020$.

Supremo Tribunal Federal. Arguição de Descumprimento de Preceito Fundamental n. 527. Requerente: Associação Brasileira de Gays, Lésbicas e Transgêneros. Ministro Relator: Luís Roberto Barroso. Brasília, 26 de junho de 2019. Disponível em: http://www.stf.jus.br/arquivo/cms/noticiaNoticiaStf/anexo/ADPF527_liminar_26jun2or 9.pdf. Acessado em I5/05/2020.

. Supremo Tribunal Federal. Recurso Extraordinário n. 670.422-RS. Recorrente: S T C. Ministro Relator: Dias Toffoli. Brasília, is ago. 2018a. Disponível em: http://portal.stf.jus.br/processos/detalhe.asp?incidente=4192182. Acessado em 27/02/2020.

DIAS, Maria Berenice. Homoafetividade e o direito à diferença. Instituto Brasileiro de Direito da Família - IBDFAM, 2007. Disponível em: http://www.ibdfam.org.br/artigos/327/Homoafetividade+e+o+direito+à+diferença. Acessado em Io/05/2020.

Homoafetividade e direitos LGBTI. 7. ed. São Paulo: Revista dos Tribunais, 2016.

LAZZARIN, Sonilde Kugel; SILVA, Gustavo Luchi da. O salário-maternidade no Brasil e as atuais configurações familiares. Revista Fórum Justiça do Trabalho, Belo Horizonte, 


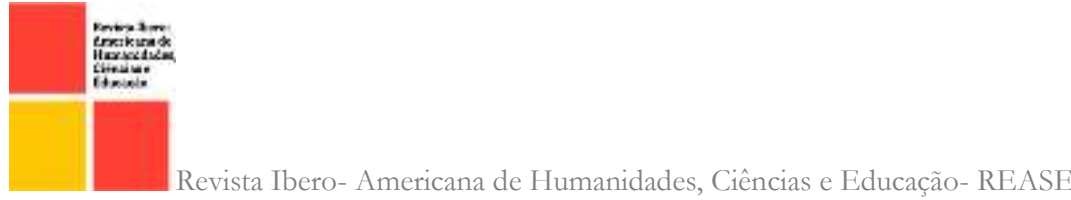

ano 36, n. 423 , p. 33-52, mar. 2019. Disponível em: https://scholar.google.com.br/scholar?hl=pt-BR\&as_sdt $=0 \%{ }_{2} \mathrm{C}_{5} \& \mathrm{q}=\mathrm{O}+\mathrm{sal} \% \mathrm{C}_{3} \%$ A Iriomaternidade + no + Brasil + e + as + atuais + configura $\% \mathrm{C}_{3} \% \mathrm{~A} 7 \% \mathrm{C}_{3} \% \mathrm{~B} 5$ es + familiares \&btnG $=$. Acessado em: 17/05/2020.

LOPES, A.L.M.D. O Direito à Identidade de Gênero e ao nome Civil dos Transexuais: Uma Análise do Atual Cenário e da Necessidade de Adequação das Normas Brasileiras. Trabalho de Conclusão de Curso apresentado como requisito para obtenção do grau de Bacharel em Ciências Jurídicas e Sociais pela PUC/RS. Porto Alegre, 2015.

RIBEIRO, Robson. O transgênero e a previdência social. Conteúdo Jurídico, Brasília: 13 de janeiro de 2020. Disponivel em: https://conteudojuridico.com.br/consulta/artigos/54127/o-transgnero-e-a-previdnciasocial. Acessado em: 13/05/2020.

SIQUEIRA, Dirceu Pereira; PUPO, N. L. S. Aposentadoria por Idade do Transgênero: Direitos de Personalidade e o Acesso à Justiça. Revista Direito e Desenvolvimento, v. 9, p. I95-206, 2018. Disponível em: https://periodicos.unipe.edu.br/index.php/direitoedesenvolvimento/article/view/874/56 2. Acessado em 28/02/2020.

SIQUEIRA, Dirceu Pereira; NUNES, Danilo Henrique. O Transgênero e o Direito Previdenciário: Omissão legislativa e insegurança jurídica no acesso aos benefícios. Revista Jus Poiesis. Rio de Janeiro, v. 2I, n. 25, 2018, p. 50-67. 29 de abril de 2018. Disponível em: http://revistaadmmade.estacio.br/index.php/jurispoiesis/article/viewFile/5022/2330.

Acessado em 29/02/2020.

SARLET, Gabrielle Bezerra Sales; REIS, Laura da Silva. Notas sobre o transgenerismo infantil: uma análise sobre os limites da autonomia corporal das crianças na perspectiva dos direitos humanos e da constitucionalização do direito civil no atual contexto brasileiro. Revista da Faculdade de Direito da UFRGS. Disponível em: https://seer.ufrgs.br/revfacdir/article/view/8418o. Acessado em 28/o2/2020.

SARLET, Ingo Wolfgang. Dignidade (da Pessoa) Humana e Direitos Fundamentais na Constituição Federal de 1988. Io. ed. Porto Alegre: Livraria do Advogado, 2019.

A eficácia dos direitos fundamentais: uma teoria geral dos direitos fundamentais na perspectiva constitucional. 13. ed. Ver. Atual e ampl. Porto alegre: Livraria do Advogado Editora, 2018. 